\title{
A Simple Approach for the Synthesis of Gold Nanoparticles Mediated by Layered Double Hydroxide
}

\author{
Aires da Conceição Silva, ${ }^{1}$ Andréa Luzia Ferreira de Souza, ${ }^{2}$ \\ Renata Antoun Simão, ${ }^{3}$ and Luiz Fernando Brum Malta ${ }^{1}$ \\ ${ }^{1}$ Instituto de Química, Universidade Federal do Rio de Janeiro, CT Bloco A, Lab 641, Rio de Janeiro, RJ 21941-909, Brazil \\ ${ }^{2}$ Instituto de Química, Universidade Federal do Rio de Janeiro, Macaé, RJ 27930-560, Brazil \\ ${ }^{3}$ Instituto Alberto Luiz Coimbra de Pós Graduação e Pesquisa de Engenharia, Universidade Federal do Rio de Janeiro, \\ CT Bloco F, Rio de Janeiro, RJ 21949-900, Brazil
}

Correspondence should be addressed to Aires da Conceição Silva; airesquimico@yahoo.com.br

Received 11 June 2013; Accepted 30 August 2013

Academic Editor: Marinella Striccoli

Copyright (C) 2013 Aires da Conceição Silva et al. This is an open access article distributed under the Creative Commons Attribution License, which permits unrestricted use, distribution, and reproduction in any medium, provided the original work is properly cited.

The present work introduces a new procedure to obtain gold nanoparticles (AuNPs). AuNPs (77-213 nm) were obtained in the absence of any classical reducing agents in a medium containing $\mathrm{Mg}^{2+} / \mathrm{Al}^{3+}$ layered double hydroxide (LDH) and $N, N$ dimethylformamide. XRD analysis showed the presence of crystalline phases of gold in the Au/LDH composite. The $2 \theta$ values of peaks corresponding to the LDH interlayer distance indicated that metallic NPs were deposited on the surface of the material. Furthermore, atomic force microscopy (AFM) analysis showed that AuNPs tend to agglomerate in a nonclassical halter-like shape.

\section{Introduction}

Metal nanoparticles (NPs) have a large surface-to-volume ratio [1-4]; therefore a large fraction of the metal atoms is on the surface available for catalysis [5]. Therefore a nanoparticle of $10 \mathrm{~nm}$ diameter has about $10 \%$ of its atoms on the surface, in contrast to a nanoparticle of $1 \mathrm{~nm}$ that has $100 \%$ [6]. This characteristic usually indicates electronic and chemical properties that differ from those of the bulk materials [7]. Gold nanoparticles (AuNPs) are promising because they have electronic, magnetic, and optical properties [8]. AuNPs also have therapeutic potential as drug-delivery carriers due to their characteristics such as size, stability, and biocompatibility [9]. Recent works have shown that the AuNP functionalization with different molecules has many applications in biomedical imaging, clinical diagnosis, and therapy, including cancer treatment [10-13].

Layered double hydroxides (LDHs) have many applications in heterogeneous catalysis as catalysts or catalyst precursors [14-17]. They are also known as anionic clays and hydrotalcite-like compounds, because structurally they are very similar to brucite $\left[\mathrm{Mg}(\mathrm{OH})_{2}\right]$, where magnesium is octahedrally surrounded by six oxygen atoms in hydroxide form. Layers are formed by sharing the edges of adjacent octahedral units, creating two-dimensional sheets that stack together to form three-dimensional structures through hydrogen bonding $[18,19]$.

Many reactants can act as reducing agents for the formation of gold nanoparticles such as cyclodextrins [8, 20, 21], sodium citrate [22, 23], hydrazine sulfate [24], and sodium borohydride $[25,26]$. Obtaining gold nanoparticles in the absence of these reactants would reduce process costs and be environmentally benign.

Herein we report an unprecedented method for the synthesis of gold nanoparticles in $N, N$-dimethylformamide (DMF) mediated by layered double hydroxide materials (LDHs).

\section{Experimental}

2.1. Materials. All chemicals were reagent-grade or analytical-grade substances when available and were used without further purification. All aqueous solutions were prepared in Milli-Q water. 


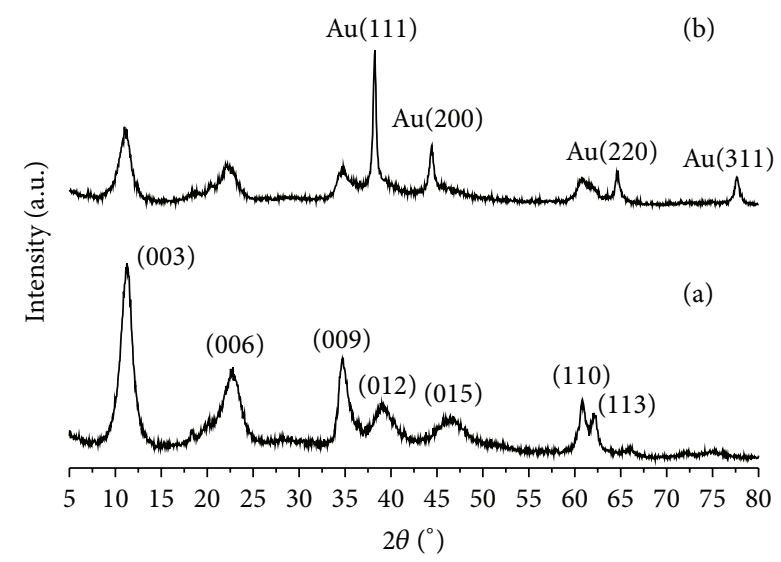

Figure 1: XRD patterns of (a) LDH and (b) Au/LDH composite.

2.2. Synthesis of $L D H$. The $\mathrm{Mg} / \mathrm{Al}$ layered double hydroxide was obtained using a solution containing $0.006 \mathrm{~mol}$ of $\mathrm{Mg}\left(\mathrm{NO}_{3}\right)_{2} \cdot 6 \mathrm{H}_{2} \mathrm{O}$ (Vetec, $99 \%$ ) and $0.003 \mathrm{~mol}$ of $\mathrm{Al}\left(\mathrm{NO}_{3}\right)_{3} \cdot 9 \mathrm{H}_{2} \mathrm{O}$ (Vetec, $\left.99 \%\right) \quad(\mathrm{Mg}(\mathrm{II}) / \mathrm{Al}(\mathrm{III})=2)$ in $100 \mathrm{~mL}$ of Milli-Q water. Under vigorous stirring, LDH was prepared by coprecipitation at constant $\mathrm{pH}(\approx 10)$ with a $1.0 \mathrm{~mol} \cdot \mathrm{L}^{-1}$ solution of $\mathrm{NaOH}$ (Vetec, 99\%) at room temperature. The suspension thus obtained was filtered, washed with Milli-Q water, and dried over a stove. The LDH was obtained as a white solid.

2.3. Synthesis of $A u / L D H$ Composite. AuNPs were prepared by adding $\mathrm{LDH}$ in a solution of $0.025 \mathrm{~mol} \cdot \mathrm{L}^{-1} \mathrm{AuCl}_{4} \cdot 2 \mathrm{H}_{2} \mathrm{O}$ (Aldrich, 99\%) in $\mathrm{N}, \mathrm{N}$-dimethylformamide (Aldrich, 99.8\%) ( $\mathrm{Au}: \mathrm{LDH} ; 1: 4)$ at $80^{\circ} \mathrm{C}$ for $24 \mathrm{~h}$. Initially, the DMF gold solution was yellow; 15 minutes after $\mathrm{LDH}$ addition to the system, the mixture started to darken, and after about 1 hour of reaction a black colored precipitate appeared. After 24 hours of reaction, the entire solution became dark. The lightly purple solid obtained was filtered, washed with portions of DMF, and dried in a properly stove.

2.4. Materials Characterization. Powder X-ray diffraction patterns were recorded on a Rigaku Ultima IV diffractometer using $\mathrm{Cu} \mathrm{K} \alpha$ radiation. Scans were performed over $2 \theta$ range from $5^{\circ}$ to $80^{\circ}$, using a resolution of $0.05^{\circ}$ and count time of $1 \mathrm{~s}$ at each point.

Fourier transform infrared spectra (FTIR) were recorded on a Nicolet Magna-IR 760 spectrophotometer with a resolution of $4 \mathrm{~cm}^{-1}$ and a number of 16 scans using wavenumber range from 400 to $4000 \mathrm{~cm}^{-1}$. Samples were prepared by mixing the powdered solids with $\mathrm{KBr}$.

Scanning electron microscope (SEM) images and energydisperse X-ray spectroscopy were performed on a JEOL JSM 6460-LV microscope operating among $10-20 \mathrm{kV}$ and equipped with an energy-disperse $\mathrm{X}$-ray spectrometer.

The atomic force microscope used was the Alpha300 AR model (WITec Instruments, GER). Images were obtained by performing in noncontact AFM mode.

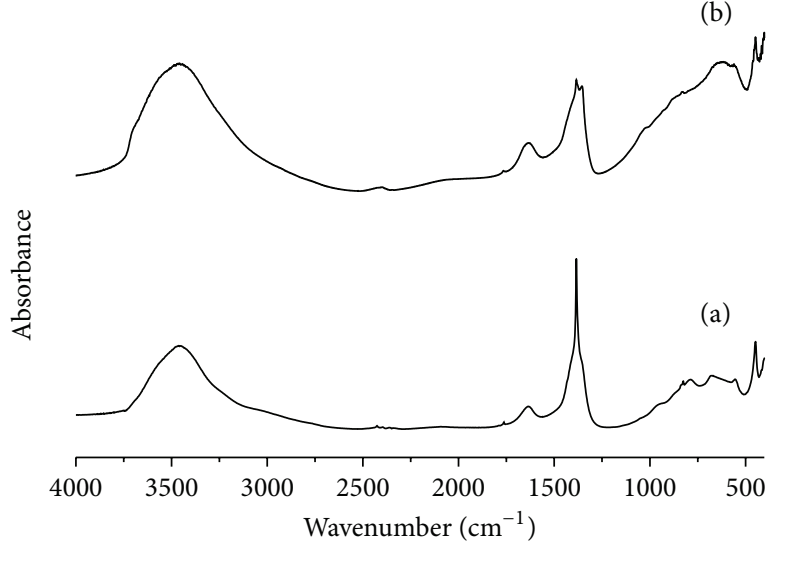

FIGURE 2: FTIR spectra for (a) LDH and (b) Au/LDH composite.

\section{Results and Discussion}

So far, the synthesis and support of gold nanoparticles on layered double hydroxide were carried out using cyclodextrins, sodium borohydride or citrate, and hydrazine sulfate as reducing agents [20-26]. When experiencing other means of metal reduction, we observed that $N, N$-dimethylformamide was not capable of reducing $\mathrm{Au}$ (III) from $\mathrm{NaAuCl}_{4}$ precursor. Layered double hydroxide was first thought as an intercalation matrix for the $\mathrm{AuCl}_{4}{ }^{-}$anion; thus at first sight, DMF would be a proper medium for this process. However, after the addition of LDH to the medium, the mixture changed its color and a dark precipitate was obtained at the end of the process. We managed to characterize this dark solid to obtain its chemical composition and microstructural and short-long range structural characteristics.

3.1. Powder X-Ray Diffraction. Figure 1 shows the XRD patterns of LDH (a) and Au/LDH composite (b). The LDH pattern (Figure 1(a)) is typical of a hydrotalcite-like material having been indexed according to the American Mineralogist card no. 0014738.

The XRD pattern of Au/LDH composite (Figure 1(b)) showed four additional peaks: a high intensity peak at $2 \theta=$ $38.2^{\circ}$ and three additional peaks at $2 \theta=44.4^{\circ}, 64.7^{\circ}$, and $77.8^{\circ}$. These reflections correspond respectively to the four planes (111), (200), (220), and (311) indicating that crystalline phases of gold were formed in the material [26, 27]. Applying the Scherrer formula:

$$
t=\frac{0,9 \lambda}{\sqrt{B m^{2}-B s^{2}} \cos \theta},
$$

where $\lambda$ is the $\mathrm{X}$-ray wavelength, $B m$ is the observed peak width, $B s$ is the peak width of a crystalline standard, and $\theta$ is the angle of diffraction; an estimate of the mean crystallite size $(t)$ of $22 \mathrm{~nm}$ for the gold phase could be obtained by considering full width at half the maximum of the four most intense reflections.

Another important detail observed when comparing these XRD profiles refers to the fact that the same interlayer distance of $8 \AA$ was obtained for both LDHs. This may 


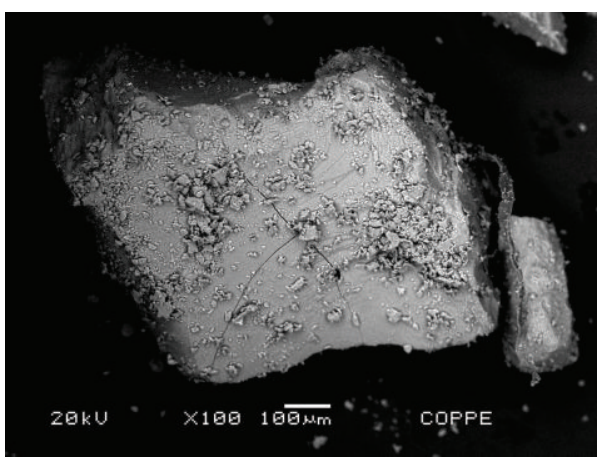

(a)

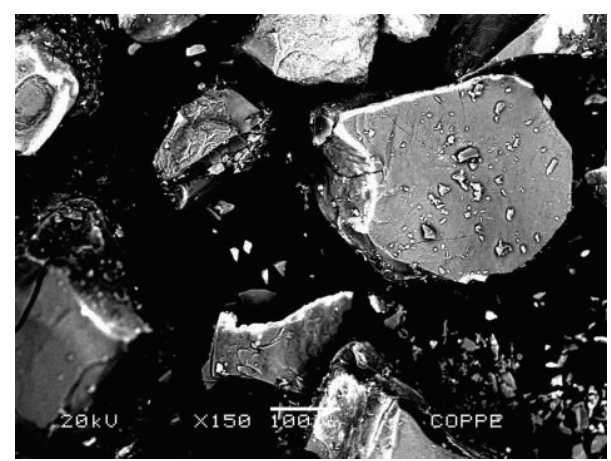

(b)

FIGURE 3: Backscattered electron images from LDH ((a) magnification: 100x) and Au/LDH composite ((b) magnification: 150x).

TABLE 1: CHN elemental analysis of $\mathrm{LDH}$ and $\mathrm{Au} / \mathrm{LDH}$ composite.

\begin{tabular}{lccc}
\hline & $\mathrm{C}(\%)$ & $\mathrm{H}(\%)$ & $\mathrm{N}(\%)$ \\
\hline LDH & 1.25 & 3.73 & 3.56 \\
$\mathrm{Au} / \mathrm{LDH}$ composite & 0.68 & 4.14 & 1.44 \\
\hline
\end{tabular}

indicate that gold particles were located primarily on the surface of LDH and not in the interlayer region [25].

\subsection{Fourier-Transform Infrared Spectroscopy. Figure 2 shows} the FTIR spectra for $\mathrm{LDH}$ and for Au/LDH composite in the region of $400-4000 \mathrm{~cm}^{-1}$. Both of them exhibit a broad band at $3500 \mathrm{~cm}^{-1}$ that can be assigned to $\mathrm{O}-$ $\mathrm{H}$ stretching, a band at $1630 \mathrm{~cm}^{-1}$ that is typical of the angle deformation vibration of the water molecule, and a band at $450 \mathrm{~cm}^{-1}$ that can be assigned to the vibrations of octahedrally coordinated $\mathrm{Al}-\mathrm{O}$ bonds. Concerning the strong band centered at $1384 \mathrm{~cm}^{-1}$ in LDH spectrum, it can be assigned as the asymmetric stretching of nitrate ion $\left(\mathrm{NO}_{3}{ }^{-}\right)$. As the absorbance of this band appeared to be reduced in the spectrum of $\mathrm{Au} / \mathrm{LDH}$ (Figure 2(b)) it may be inferred that ion exchange process occurred, corroborating the $\mathrm{CHN}$ elemental analysis (Table 1), which indicated a decrease in the amount of nitrogen (from $\mathrm{NO}_{3}{ }^{-}$) for $\mathrm{Au} / \mathrm{LDH}$ composite in face of $\mathrm{LDH}$.

\subsection{Scanning Electron Microcopy and X-Ray Energy Dispersive} Spectroscopy. Both micrographs in Figure 3 are visualizations of $\mathrm{LDH}$ and $\mathrm{Au} / \mathrm{LDH}$ composite using backscattered electrons signals. Both images show agglomerates greater than $100 \mu \mathrm{m}$. The left micrograph was obtained from LDH, and no phase contrast was detected while the right image was taken from the $\mathrm{Au} / \mathrm{LDH}$ composite and showed different phases by evidence of different shades of gray. The bright spots seen are related to the metallic phase $(\mathrm{Au})$. This was confirmed by EDX analysis of $\mathrm{Au} / \mathrm{LDH}$ composite (Figure 4) which reveals heterogeneous distribution of gold in the material (Figure 4-Pt.1). Here it is also important to note that $\mathrm{Mg}$ intensity is always greater than that of $\mathrm{Al}$, as expected by the proposed synthesis of LDH. Another important feature is related to the unexpected presence of chloride ion in the $\mathrm{Au} / \mathrm{LDH}$ material (see EDX spectra of Figure 4). In addition, the chloride ion seems to be homogeneously distributed in the LDH matrix since it was detected for all the three regions probed. One explanation for this considers that chloride ion was intercalated by ion-exchange process with nitrate ion, considering that FTIR and CHN analysis showed a decrease of $\mathrm{NO}_{3}{ }^{-}$in $\mathrm{Au} / \mathrm{LDH}$ composite in face of $\mathrm{LDH}$ sample.

3.4. Atomic Force Microscopy. In order to gain some microstructure information concerning the gold particles deposited on $\mathrm{LDH}$, we managed to obtain atomic force micrographs. Figures 5(a) and 5(b) correspond to the phase and topography images, respectively. It is clearly shown that black spots in the phase image correspond to the highest heights in the topography image (the "whiter" spots), and therefore it is possible to identify them as the gold nanoparticles deposited on LDH matrix. These particles present size distribution from 77 to $231 \mathrm{~nm}$ and are constituted by agglomeration of smaller gold crystallites, considering the mean crystallite size of $22 \mathrm{~nm}$ obtained from the XRD pattern of $\mathrm{Au} / \mathrm{LDH}$ composite.

In Scheme 1, we show a proposal for the mechanism of the formation of gold nanoparticles in which we suggest that DMF, besides being the solvent, is the reducing agent in a redox process mediated by LDH.

\section{Conclusion}

So far this work is the first attempt to prepare gold nanoparticles without an effective reducing agent in the reaction. We believe that metal reduction occurred by means of reaction with the solvent, $\mathrm{N}, \mathrm{N}$-dimethylformamide, mediated by layered double hydroxide. This can be affirmed based on the experimental observation that while no color change was observed even in a long period after mixing $\mathrm{NaAuCl}_{4}$ with DMF, a dark heterogeneous mixture began to form immediately upon addition of $\mathrm{LDH}$. As a parallel process, chloride ion generated from $\mathrm{AuCl}_{4}{ }^{-}$was intercalated in the LDH matrix by the ion-exchange process with nitrate ion. This work described the method to constitute in a simple way gold nanoparticles supported on LDH that can be applied as 

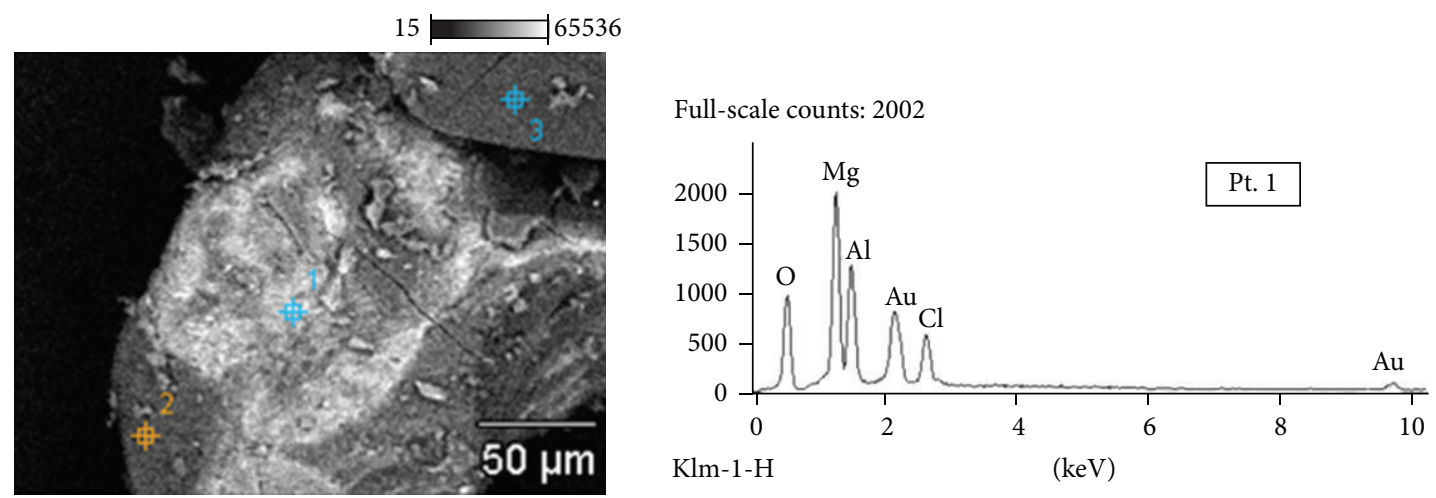

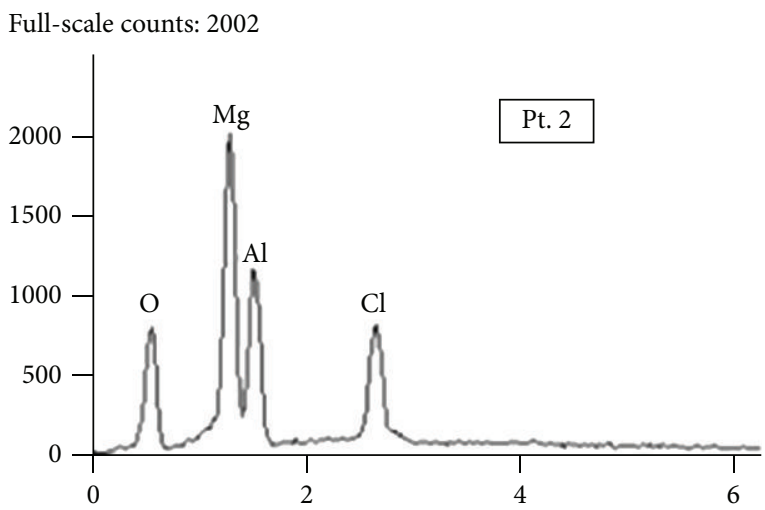

Klm-1-H (keV)
Full-scale counts: 2004

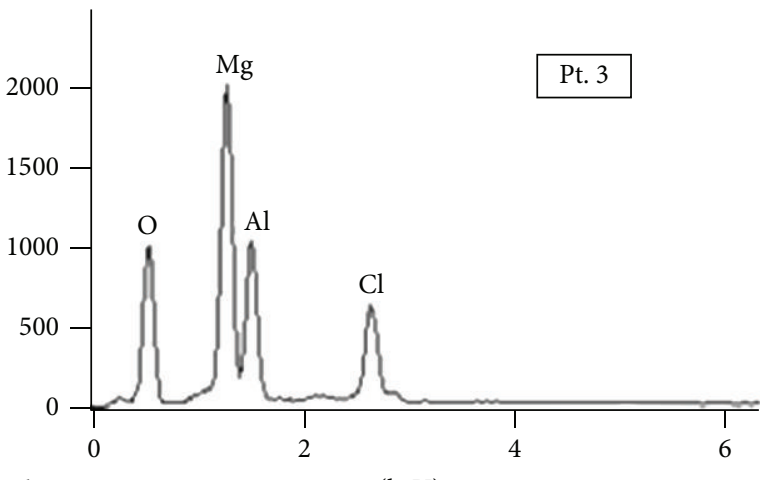

Klm-1-H

(keV)

FIGURE 4: EDX spectra related to the three points probed in the SEM image of Au/LDH composite.

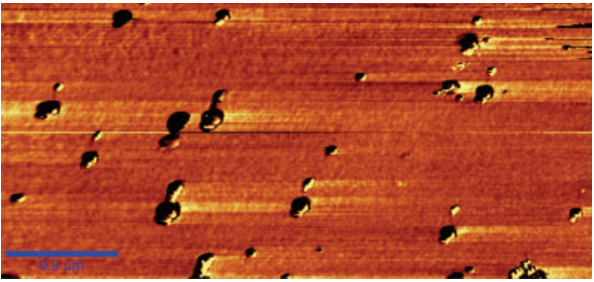

(a)

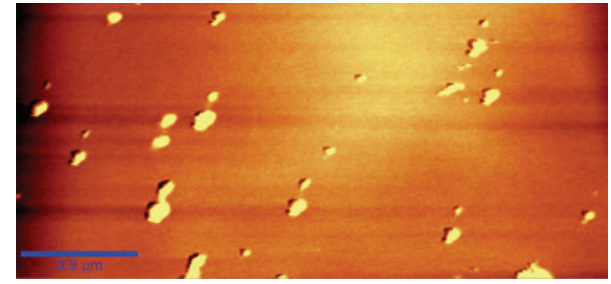

(b)

Figure 5: (a) Phase and (b) topography images obtained for Au/LDH composite with atomic force microscopy.
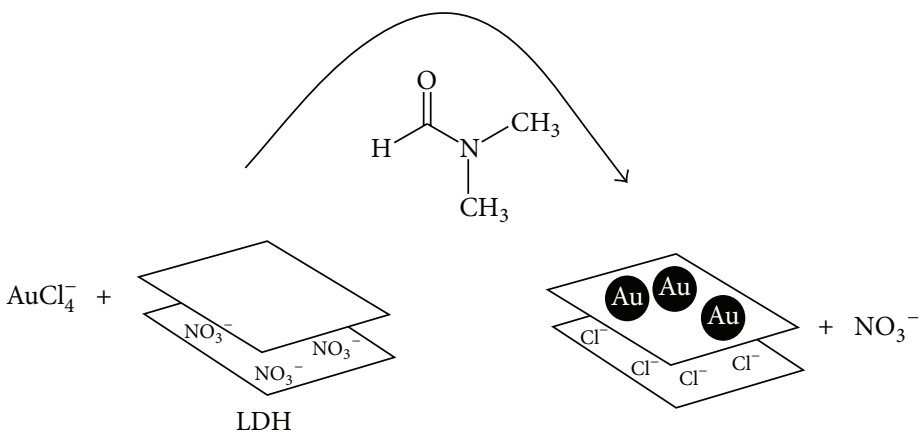

Scheme 1: Proposal for the formation of gold nanoparticles mediated by LDH and $N, N$-dimethylformamide. 
composites for organometallic catalysis [28], drug delivery systems [29] and clinical diagnosis [30].

\section{Acknowledgments}

The authors thank the financial support from CNPq (Process 473754/2010-0), CAPES, and FAPERJ.

\section{References}

[1] C. Xue, K. Palaniappan, G. Arumugam, S. A. Hackney, J. Liu, and H. Liu, "Sonogashira reactions catalyzed by water-soluble, $\beta$-cyclodextrin-capped palladium nanoparticles," Catalysis Letters, vol. 116, no. 3-4, pp. 94-100, 2007.

[2] C. Feng, L. Guo, Z. Shen et al., "Synthesis of short palladium nanoparticle chains and their application in catalysis," Solid State Sciences, vol. 10, no. 10, pp. 1327-1332, 2008.

[3] T. S. Huang, Y. H. Wang, J. Y. Jiang, and Z. L. Jin, "PEGstabilized palladium nanoparticles: an efficient and recyclable catalyst for the selective hydrogenation of 1,5-cyclooctadiene in thermoregulated PEG biphase system," Chinese Chemical Letters, vol. 19, no. 1, pp. 102-104, 2008.

[4] B. C. Ranu, R. Dey, and K. Chattopadhyay, "A one-pot efficient and fast Hiyama coupling using palladium nanoparticles in water under fluoride-free conditions," Tetrahedron Letters, vol. 49, no. 21, pp. 3430-3432, 2008.

[5] S.-W. Kim, J. Park, Y. Jang et al., "Synthesis of monodisperse palladium nanoparticles," Nano Letters, vol. 3, no. 9, pp. 12891291, 2003.

[6] M. Moreno-Mañas and R. Pleixats, "Formation of carboncarbon bonds under catalysis by transition-metal nanoparticles," Accounts of Chemical Research, vol. 36, no. 8, pp. 638-643, 2003.

[7] C.-C. Wang, D.-H. Chen, and T.-C. Huang, "Synthesis of palladium nanoparticles in water-in-oil microemulsions," Colloids and Surfaces A, vol. 189, no. 1-3, pp. 145-154, 2001.

[8] J. Bai, Q. Yang, M. Li, S. Wang, C. Zhang, and Y. Li, "Preparation of composite nanofibers containing gold nanoparticles by using poly( $N$-vinylpyrrolidone) and $\beta$-cyclodextrin," Materials Chemistry and Physics, vol. 111, no. 2-3, pp. 205-208, 2008.

[9] G. Han, P. Ghosh, M. De, and V. M. Rotello, "Drug and gene delivery using gold nanoparticles," Nanobiotechnology, vol. 3, no. 1, pp. 40-45, 2007.

[10] C. Park, H. Youn, H. Kim et al., "Cyclodextrin-covered gold nanoparticles for targeted delivery of an anti-cancer drug," Journal of Materials Chemistry, vol. 19, no. 16, pp. 2310-2315, 2009.

[11] A. Kumar, H. Ma, X. Zhang et al., "Gold nanoparticles functionalized with therapeutic and targeted peptides for cancer treatment," Biomaterials, vol. 33, no. 4, pp. 1180-1189, 2012.

[12] C. R. Patra, R. Bhattacharya, D. Mukhopadhyay, and P. Mukherjee, "Fabrication of gold nanoparticles for targeted therapy in pancreatic cancer," Advanced Drug Delivery Reviews, vol. 62, no. 3, pp. 346-361, 2010.

[13] H. Wang, L. Zheng, C. Peng et al., "Computed tomography imaging of cancer cells using acetylated dendrimer-entrapped gold nanoparticles," Biomaterials, vol. 32, no. 11, pp. 2979-2988, 2011.

[14] Z. P. Xu, J. Zhang, M. O. Adebajo, H. Zhang, and C. Zhou, "Catalytic applications of layered double hydroxides and derivatives," Applied Clay Science, vol. 53, no. 2, pp. 139-150, 2011.
[15] M. Mora, C. Jiménez-Sanchidrián, and J. R. Ruiz, "Heterogeneous Suzuki cross-coupling reactions over palladium/hydrotalcite catalysts," Journal of Colloid and Interface Science, vol. 302, no. 2, pp. 568-575, 2006.

[16] D. Francová, N. Tanchoux, C. Gérardin et al., "Hydrogenation of 2-butyne-1,4-diol on supported Pd catalysts obtained from LDH precursors," Microporous and Mesoporous Materials, vol. 99, no. 1-2, pp. 118-125, 2007.

[17] C. Jiménez-Sanchidrián, M. Mora, and J. R. Ruiz, "Suzuki cross-coupling reaction over a palladium-pyridine complex immobilized on hydrotalcite," Catalysis Communications, vol. 7, no. 12, pp. 1025-1028, 2006.

[18] R. D. Hetterley, R. Mackey, J. T. A. Jones, Y. Z. Khimyak, A. M. Fogg, and I. V. Kozhevnikov, "One-step conversion of acetone to methyl isobutyl ketone over Pd-mixed oxide catalysts prepared from novel layered double hydroxides," Journal of Catalysis, vol. 258, no. 1, pp. 250-255, 2008.

[19] S. Liu, X. Jiang, and G. Zhuo, "Heck reaction catalyzed by colloids of delaminated Pd-containing layered double hydroxide," Journal of Molecular Catalysis A, vol. 290, no. 1-2, pp. 72-78, 2008.

[20] J. Liu, J. Alvarez, W. Ong, E. Román, and A. E. Kaifer, "Phase transfer of hydrophilic, cyclodextrin-modified gold nanoparticles to chloroform solutions," Journal of the American Chemical Society, vol. 123, no. 45, pp. 11148-11154, 2001.

[21] Y. Liu, K. B. Male, P. Bouvrette, and J. H. T. Luong, "Control of the size and distribution of gold nanoparticles by unmodified cyclodextrins," Chemistry of Materials, vol. 15, no. 22, pp. 41724180, 2003.

[22] S. Rodríquez-Llamazares, P. Jara, N. Yutronic, M. Noyong, J. Bretschneider, and U. Simon, "Face preferred deposition of gold nanoparticles on $\alpha$-cyclodextrin/octanethiol inclusion compound," Journal of Colloid and Interface Science, vol. 316, no. 1, pp. 202-205, 2007.

[23] Y. Wang, D. Zhang, M. Tang, S. Xu, and M. Li, "Electrocatalysis of gold nanoparticles/layered double hydroxides nanocomposites toward methanol electro-oxidation in alkaline medium," Electrochimica Acta, vol. 55, no. 12, pp. 4045-4049, 2010.

[24] B. Streszewski, W. Jaworski, K. Pacławski, E. Csapó, I. Dékány, and K. Fitzner, "Gold nanoparticles formation in the aqueous system of gold(III) chloride complex ions and hydrazine sulfateKinetic studies," Colloids and Surfaces A, vol. 397, pp. 63-72, 2012.

[25] L. Jin, D. He, Z. Li, and M. Wei, "Protein adsorption on gold nanoparticles supported by a layered double hydroxide," Materials Letters, vol. 77, pp. 67-70, 2012.

[26] L. Wang, X. Meng, and F. Xiao, "Au nanoparticles supported on a layered double hydroxide with excellent catalytic properties for the aerobic oxidation of alcohols," Chinese Journal of Catalysis, vol. 31, no. 8, pp. 943-947, 2010.

[27] V. Belova, H. Möhwald, and D. G. Shchukin, "Sonochemical intercalation of preformed gold nanoparticles into multilayered clays," Langmuir, vol. 24, no. 17, pp. 9747-9753, 2008.

[28] D. K. Dumbre, P. N. Yadav, S. K. Bhargava, and V. R. Choudhary, "Suzuki-Miyaura cross-coupling reaction between aryl halides and phenylboronic acids over gold nano-particles supported on $\mathrm{MgO}$ (or $\mathrm{CaO}$ ) and other metal oxides," Journal of Catalysis, vol. 301, pp. 134-140, 2013.

[29] L. Wang, H. Xing, S. Zhang et al., "A Gd-doped Mg-Al$\mathrm{LDH} / \mathrm{Au}$ nanocomposite for CT/MR bimodal imagings and simultaneous drug delivery," Biomaterials, vol. 34 , no. 13, pp. 3390-3401, 2013. 
[30] A. Kumar, B. Mazinder Boruah, and X.-J. Liang, "Gold nanoparticles: promising nanomaterials for the diagnosis of cancer and HIV/AIDS," Journal of Nanomaterials, vol. 2011, Article ID 202187, 17 pages, 2011. 

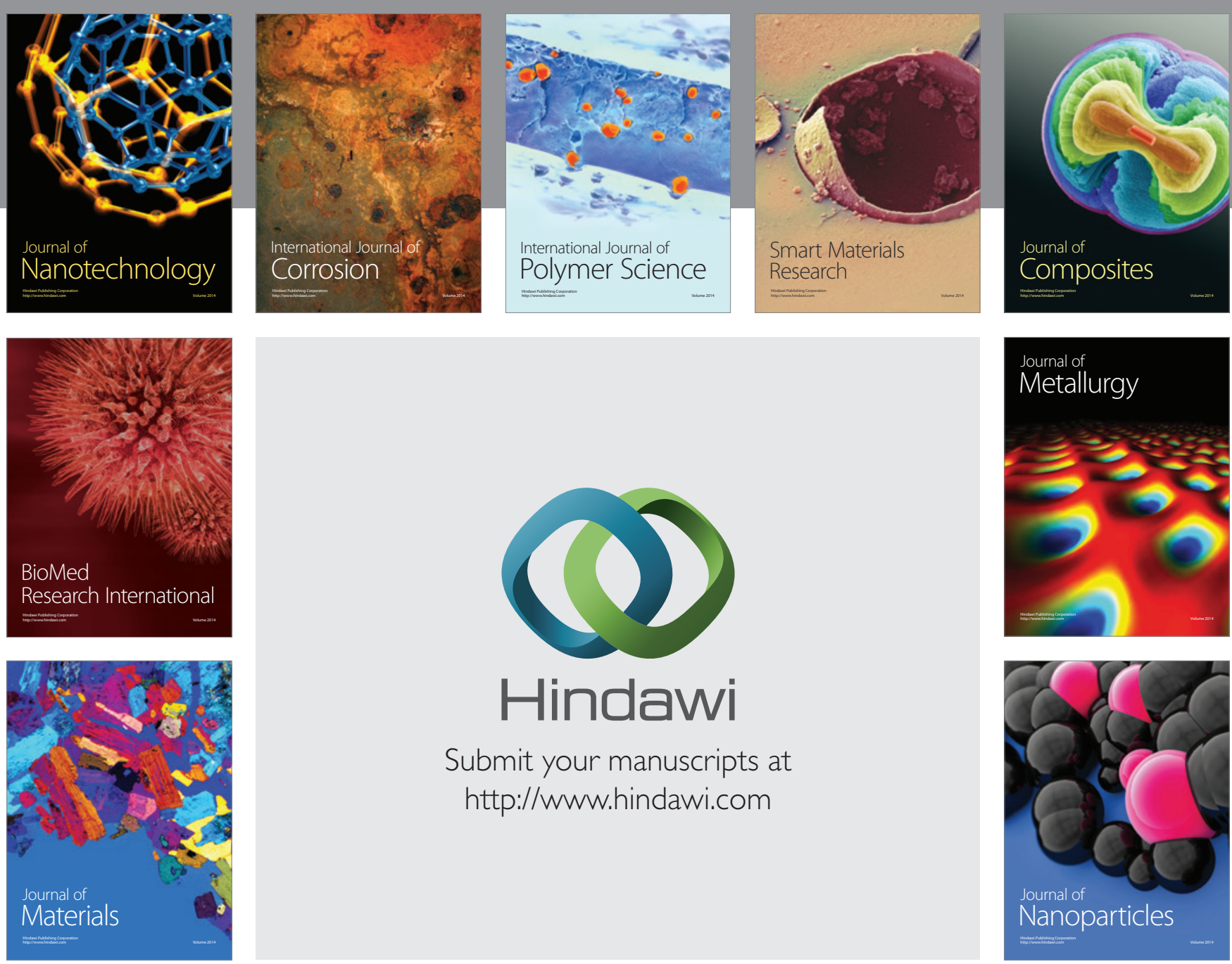

Submit your manuscripts at http://www.hindawi.com
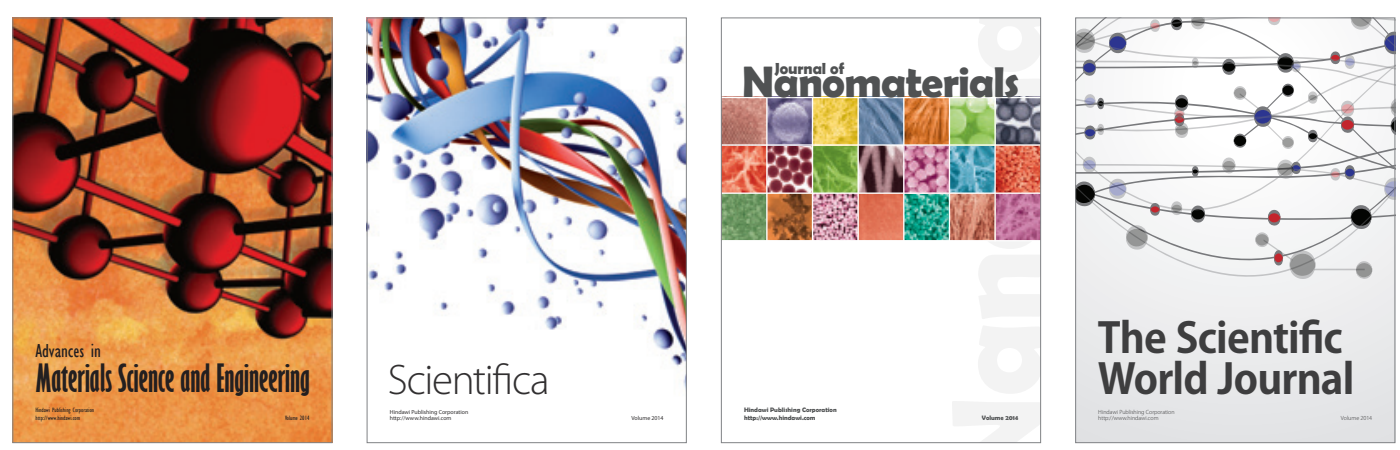

\section{The Scientific World Journal}
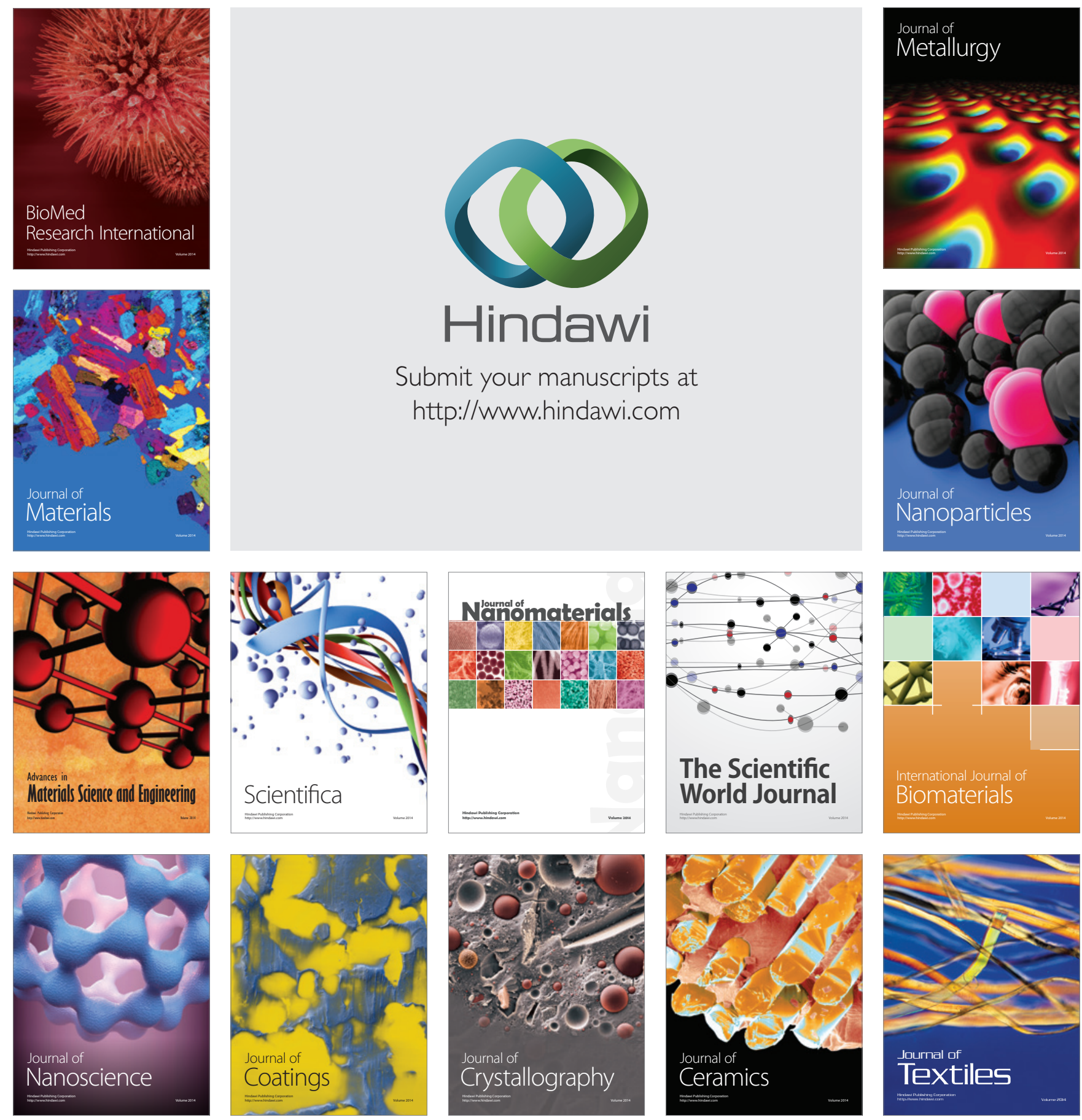